Development and Validation of a Rapid Multi-class Method for the Confirmation of Fourteen Prohibited Medicinal Additives in Pig and Poultry Compound Feed by Liquid Chromatography Tandem Mass Spectrometry

\author{
Mark Cronly \\ Technological University Dublin, mark.cronly@statelab.ie \\ Patrice Behan \\ Technological University Dublin, patrice.behan@tudublin.ie \\ Barry Foley \\ Technological University Dublin, Barry.foley@tudublin.ie
}

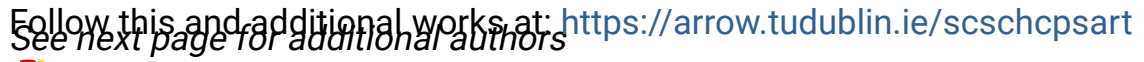

Part of the Analytical Chemistry Commons, Food Chemistry Commons, Other Analytical, Diagnostic and Therapeutic Techniques and Equipment Commons, and the Other Chemicals and Drugs Commons

\begin{abstract}
Recommended Citation
Cronly, M. et al:Development and Validation of a Rapid Multi-class Method for the Confirmation of Fourteen Prohibited Medicinal Additives in Pig and Poultry Compound Feed by Liquid Chromatography Tandem Mass Spectrometry.Journal of Pharmaceutical and Biomedical Analysis; (2010), 53:929-938. doi:10.1016/j.jpba.2010.06.027
\end{abstract}

This Article is brought to you for free and open access by the School of Chemical and Pharmaceutical Sciences at ARROW@TU Dublin. It has been accepted for inclusion in Articles by an authorized administrator of ARROW@TU Dublin. For more information, please contact arrow.admin@tudublin.ie, aisling.coyne@tudublin.ie, gerard.connolly@tudublin.ie.

Funder: Strand 1, State Laboratory

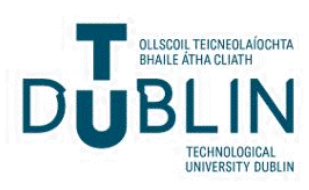




\section{Authors}

Mark Cronly, Patrice Behan, Barry Foley, Liam Regan, Marella Gallagher, Sean Earley, Paula Shearan, and Edward Malone 


\title{
DEVELOPMENT AND VALIDATION OF A RAPID MULTI-CLASS METHOD FOR THE CONFIRMATION OF FOURTEEN PROHIBITED MEDICINAL ADDITIVES IN PIG AND POULTRY COMPOUND FEED BY LIQUID CHROMATOGRAPHY TANDEM MASS SPECTROMETRY
}

\author{
Author Name Mark Cronly, ${ }^{\star a, b}$ Patrice Behan ${ }^{a}$, Barry Foley ${ }^{a}$, Marella Gallagher ${ }^{b}$ Sean Earley ${ }^{b}$ \\ Paula Shearan ${ }^{b}$ Edward Malone $^{b}$ and Liam Regan ${ }^{b}$
}

\begin{abstract}
A confirmatory method has been developed to allow for the analysis of fourteen prohibited medicinal additives in pig and poultry compound feed. These compounds are prohibited for use as feed additives although some are still authorised for use in medicated feed. Feed samples are extracted by acetonitrile with addition of sodium sulphate. The extracts undergo a hexane wash to aid with sample purification. The extracts are then evaporated to dryness and reconstituted in initial mobile phase. The samples undergo an ultracentrifugation step prior to injection onto the LC-MS/MS system and are analysed in a run time of 26 minutes. The LC-MS/MS system is run in MRM mode with both positive and negative electrospray ionisation. The method was validated over three days and is capable of quantitatively analysing for metronidazole, dimetridazole, ronidazole, ipronidazole, chloramphenicol, sulfadiazine, sulfamethazine, dinitolimide, ethopabate, carbadox and clopidol. The method is also capable of qualitatively analysing for tylosin, virginiamycin and avilamycin. A level of 100 $\mu \mathrm{g} \mathrm{kg}{ }^{-1}$ was used for validation purposes and the method is capable of analysing to this level for all the compounds. Validation criteria of trueness, precision, repeatability and reproducibility along with measurement uncertainty are calculated for all analytes.
\end{abstract}

Keywords: Antibiotics; pig and poultry compound feed; Ic-ms/ms; validation.

\section{Introduction}

The use of many antibiotics, coccidiostats and antibacterial growth promoters as feed additives has been prohibited in Europe since 2006 by Commission Recommendation 2005/925/EC. This recommendation lists medicinal substances that should be monitored and the substances are divided into two groups; medicinal substances authorised as feed additives for certain animal species or categories and medicinal substances no longer authorised as feed additives. This paper focuses on the analysis of the second group of medicinal substances specifically antibacterial growth promoters (AGPs) which are no longer authorised as feed additives; this group consists of various different types of compounds. Nitroimidazoles and chloramphenicol are banned for use in food producing animals. Other AGPs which include virginiamycin and tylosin are prohibited for use as feed additives. Finally some compounds such as sulfonamides are only permitted for use in medicated feed. The structures for all fourteen analytes are presented in Tables $1 \mathrm{a}$ and $1 \mathrm{~b}$.

\footnotetext{
a Dublin Institute of Technology, School of Chemical and Pharmaceutical Sciences, Kevin Street, Dublin 8, Ireland ${ }^{b}$ State Laboratory, Young's Cross, Backweston Campus, Backweston, Celbridge, Co. Kildare, Ireland. Fax: 01505 7384; Tel: 01505 7384; E-mail: mark.cronly@statelab.ie
}

Nitroimidazoles and chloramphenicol are classified as prohibited substances in table 2 of Commission Regulation 2010/37/EC and therefore prohibited for the use in animal husbandry. As a result these should not be found in animal feeds. While there are single class methods for the analysis of some of compounds [Vincent et al., 2008; Galarini et al., 2009; Pecorelli et al., 2003; Barbosa et al., 2007; van Holthoon et al., 2010] there are very few published methods for nitroimidazoles and chloramphenicol in animal feed. Capitan-Vallvey et al., 2007 describes a method for the analysis of nitroimidazoles in feed by LC-MS and Vinas et al., 2006 describes a method for chloramphenicol in feed by LCphoto diode array detector. The use of 5 AGPs including tylosin and virginiamycin were prohibited for this use in Council Regulation 2821/98. As a result there are some published methods for the analysis of these compounds. Van Poucke et al. described a method for the analysis of tylosin and virginiamycin in feed by LC-MS/MS [Van Poucke et al., 2003 Van Poucke et al., 2005] and Civitareale et al., 2004 describes a method for the analysis of tylosin by LC-UV/DAD. Other medicinal additives listed in 2005/925/EC also have LC methods for their analysis such as clopidol/nicarbazin [Dusi et al., 2000], amprolium/ethopabate [Tan et al., 1996] and carbadox [Kesiunaite et al., 2008; Hutchinson et al., 2005] while for compounds such as dinitolimide no 
Table 1a: Molecular Structures, Retention time (Rt),

Precursor and Product ions and typical ion ratios for all

11 analytes

\begin{tabular}{|c|c|c|c|c|c|}
\hline Compound & Molecular Structure & $\mathrm{Rt}$ & $\begin{array}{l}\text { Precursor } \\
\text { Ion }(\mathrm{M} / \mathrm{z})\end{array}$ & $\begin{array}{l}\text { Product } \\
\text { Ions }(\mathrm{M} / \mathrm{z})\end{array}$ & $\begin{array}{l}\text { Collision } \\
\text { Energy }\end{array}$ \\
\hline \multirow{2}{*}{$\begin{array}{c}\text { Ipronidazole (IPZ) } \\
\text { 2-isopropyl-1-methyl-5-nitroimidazole }\end{array}$} & & \multirow{2}{*}{9.90} & \multirow{2}{*}{170} & 124 & 18 \\
\hline & & & & 109 & 25 \\
\hline \multirow{2}{*}{$\begin{array}{l}\text { Dimetridazole (DMZ) } \\
\text { 1, 2-dimethyl-5-nitroimidazole }\end{array}$} & & \multirow{2}{*}{2.83} & \multirow{2}{*}{142} & 96 & 18 \\
\hline & & & & 81 & 28 \\
\hline \multirow{2}{*}{$\begin{array}{l}\text { Metronidazole (MNZ) } \\
\text { 1-(2-hydroxyethyl)-2-methyl-5- } \\
\text { nitroimidazole }\end{array}$} & & \multirow{2}{*}{1.95} & \multirow{2}{*}{172} & 82 & 25 \\
\hline & & & & 128 & 15 \\
\hline \multirow{2}{*}{$\begin{array}{c}\text { Ronidazole (RNZ) } \\
\text { 1-methyl-2-[(carbamoyloxy) methyl]- } \\
\text { 5-nitroimidazole }\end{array}$} & & \multirow{2}{*}{2.21} & \multirow{2}{*}{201} & 140 & 15 \\
\hline & & & & 110 & 18 \\
\hline \multirow{2}{*}{$\begin{array}{c}\text { Chloramphenicol (CAP) } \\
\text { 2,2-dichloro-N-[(1R,2R)-2-hydroxy-1- } \\
\text { (hydroxymethyl)-2-(4- } \\
\text { nitrophenyl)ethyl]acetamide }\end{array}$} & & \multirow{2}{*}{13.46} & \multirow{2}{*}{321} & 257 & 18 \\
\hline & & & & 152 & 12 \\
\hline \multirow{2}{*}{$\begin{array}{l}\text { Sulfadiazine (SDZ) } \\
\text { 4-amino-N-pyrimidin- 2-yl- } \\
\text { benzenesulfonamide }\end{array}$} & & \multirow{2}{*}{2.39} & \multirow{2}{*}{251} & 110 & 23 \\
\hline & & & & 156 & 17 \\
\hline \multirow{2}{*}{$\begin{array}{l}\text { Sulfamethazine (SMZ) } \\
\text { 2-(p-Aminobenzenesulfonamido)-4,6- } \\
\text { dimethylpyrimidine }\end{array}$} & & \multirow{2}{*}{4.29} & \multirow{2}{*}{279} & 186 & 17 \\
\hline & & & & 156 & 19 \\
\hline \multirow{2}{*}{$\begin{array}{l}\text { Ethopabate (EPB) } \\
\text { methyl 4-(acetylamino)-2- } \\
\text { ethoxybenzoate }\end{array}$} & & \multirow{2}{*}{14.16} & \multirow{2}{*}{238} & 136 & 32 \\
\hline & & & & 206 & 13 \\
\hline \multirow{2}{*}{$\begin{array}{c}\text { Clopidol (CLOP) } \\
\text { 3,5-Dichloro-2,6-dimethyl-pyridin-4-ol }\end{array}$} & & \multirow{2}{*}{2.00} & \multirow{2}{*}{192} & 128 & 24 \\
\hline & & & & 101 & 26 \\
\hline \multirow{2}{*}{$\begin{array}{c}\text { Carbadox (CAR) } \\
\text { methyl (2E)-2-[(1,4-dioxidoquinoxalin- } \\
2-\mathrm{yl}) \\
\text { methylene]hydrazinecarboxylate }\end{array}$} & & \multirow{2}{*}{2.65} & \multirow{2}{*}{263} & 175 & 19 \\
\hline & & & & 130 & 22 \\
\hline \multirow[b]{2}{*}{$\begin{array}{l}\text { Dinitolmide (DIN) } \\
\text { 2-Methyl-3,5-dinitrobenzamide }\end{array}$} & & \multirow[b]{2}{*}{7.68} & \multirow[b]{2}{*}{224} & 151 & 18 \\
\hline & $\ddot{6}$ & & & 181 & 12 \\
\hline
\end{tabular}


Table 1b: Molecular Structures, Retention time (Rt), Precursor and Product ions and collision energies for all 3 analytes.

\begin{tabular}{|c|c|c|c|c|c|}
\hline Compound & Molecular Structure & Rt & $\begin{array}{l}\text { Precursor } \\
\text { Ion }(M / z)\end{array}$ & $\begin{array}{l}\text { Product lons } \\
\qquad(\mathrm{M} / \mathrm{z})\end{array}$ & $\begin{array}{c}\text { Collision } \\
\text { Energy }\end{array}$ \\
\hline \multirow{2}{*}{ Tylosin (TYL) } & & \multirow{2}{*}{14.03} & \multirow{2}{*}{917} & 772 & 29 \\
\hline & & & & 174 & 37 \\
\hline \multirow{2}{*}{ Viginiamycin (VIR) } & & \multirow{2}{*}{16.12} & \multirow{2}{*}{526} & 355 & 20 \\
\hline & & & & 508 & 15 \\
\hline \multirow{3}{*}{ Avilamycin (AVIL) } & & \multirow{3}{*}{14.89} & \multirow{3}{*}{791} & 373 & 45 \\
\hline & & & & & \\
\hline & & & & 391 & 48 \\
\hline
\end{tabular}

published methods exist for their analysis. The majority of methods published for the list of compounds specified in 2005/925/EC allow for the analysis of these compounds at levels relating to therapeutic level or in the $\mathrm{mg} \mathrm{kg}^{-1}$ range while only a few allow for the analysis in the $\mu \mathrm{g} \mathrm{kg}^{-1}$ range. Also, from examination of literature the majority of methods are single or dual analyte methods while very few are capable of analysing for a particular class of compounds.

From a review of the literature it would seem there is a lack of published methods available that would help with the enforcement of Commission Recommendation $2005 / 925 /$ EC. In addition to this, methods available are for single analytes/classes at $\mathrm{mg} \mathrm{kg}^{-1}$ range; often utilising large sample sizes which in turn need large amounts of solvent for extraction which can prove expensive and time consuming. Reports from the Screening and Identification Methods for official control of Banned Antibiotics and Growth promoters in Feedingstuffs study (SIMBAG-FEED study) suggested that methods be able to identify compounds to at least 5 times lower than the lowest contents formerly described in the Directive 70/524/CEE. In many cases this was around the $1 \mathrm{ppm}$ range [de Jong, 2005]. To aid compliance with Commission Recommendation 2005/925/EC there is a need for an efficient sensitive multi-class method to analyse for as many of the analytes listed in this recommendation as possible. To this end; this paper describes the analysis of 14 of these prohibited medicinal additives at $100 \mathrm{\mu g} \mathrm{kg}^{-1}$ levels in pig and poultry compound feed by LC-MS/MS utilising a small sample size of $2 \mathrm{~g}$ and an efficient sample extraction procedure.

\section{Materials and Methods}

\subsection{Chemicals and Reagents}

Dimetridazole (DMZ), ronidazole (RNZ), chloramphenicol (CAP), sulfadiazine (SDZ), sulfamethazine (SMZ), dinitolimide (DIN), ethopabate (ETHO), carbadox (CAR), clopidol (CLOP) and sulfaphenazole (SPZ) were purchased from Sigma (St. Louis, MO, USA), metronidazole (MNZ), ipronidazole(IPZ), d3-IPZ, d3DMZ, d3-RNZ were purchased from WITEGA Laboratorien (Berlin, Germany), d5-chloramphenicol were purchased from Dr Ehrenstorfer (Augsborg, Germany) and tylosin, virginiamycin and avilamycin were received from RIKILT (Wageningen, The Netherlands). Water was of LC-MS grade from Fluka (Germany). All other solvents were of LC grade and purchased from Reagecon (Clare, Ireland). Anhydrous Sodium sulphate 
was AnalaR grade and purchased from Acros (Geel, Belgium). Individual stock standards of each analyte ranging between $0.25-1.00 \mathrm{mg} \mathrm{ml}^{-1}$ in ethanol were prepared and stored at $4^{\circ} \mathrm{C}$. A working standard solution (mixture of analytes) (10 ug mL $\mathrm{m}^{-1}$ ) was prepared in acetonitrile and stored at $4^{\circ}$. Internal standards were prepared similarly except mixed standard was $200 \mathrm{ng}$ $\mathrm{mL}^{-1}$.

\subsection{Instrumentation}

The LC-MS/MS system was a TSQ Quantum Ultra EMR coupled to a Finnigan Surveyor LC system. The instrument was controlled by Xcalibur software (Version 1.5). Separation was achieved using a $\left(100^{\prime} 2\right) \mathrm{mm}$, $3 \mathrm{~mm}$ particle size, Luna C18 column (Part No. 00D4251-B0) protected by a Security Guard guard cartridge system $\left(20^{\prime} 2\right) \mathrm{mm}$, both supplied by Phenomenex. The oven temperature was set at $40^{\circ} \mathrm{C}$. The chromatographic separation was performed in gradient mode using water acidified with $0.2 \%$ acetic acid (mobile phase A) and acetonitrile acidified with $0.2 \%$ acetic acid (mobile phase $B$ ), at a flow rate of $0.25 \mathrm{~mL} \mathrm{~min}$. The initial conditions from $0-6 \mathrm{~min}$ were $85 \% \mathrm{~A}$. This was changed to $50 \% \mathrm{~A}$ over 2 minutes from 6-8min and was maintained until 10 $\mathrm{min}$. The conditions were changed again to $10 \% \mathrm{~A}$ over 2 minutes from 10-12 min and these were maintained until $15.20 \mathrm{~min}$. Finally the conditions returned to $85 \% \mathrm{~A}$ over 2.8 minutes from $15.20-18 \mathrm{~min}$ and were maintained until the end of the run at $26 \mathrm{~min}$. Electrospray ionisation (ESI) was used in the MS with both positive and negative ionisation mode, with a spray voltage of $4350 \mathrm{~V}$ and a cone temperature of $325{ }^{\circ} \mathrm{C}$. The individual precursor and products ions for each analyte with their respective collision energies are listed in Tables $1 \mathrm{a}$ and $1 b$.

\subsection{Pig and Poultry Compound Feed Samples}

Different varieties of pig and poultry compound feed were sourced from various feed mills. These were milled upon receipt to $1 \mathrm{~mm}$ using a Retsch SM 100 mill and stored in amber jars at $4^{\circ} \mathrm{C}$. Portions of these samples were analysed and those found to contain no detectable residues of the analytes of interest except for residues of sulfadiazine were used as blanks for the validation study. To ensure true robustness of the method a high number of different feed samples were used in validation. These included 18 different pig feeds and 18 different poultry feeds. Chromatograms of blank feed can be seen in Figure $1 b$.

\section{$2.4 \quad$ Extraction}

Feed ( $2 \mathrm{~g}$ ) was weighed into polypropylene centrifuge tubes $(50 \mathrm{~mL})$. The sample was fortified with mixed internal standard $(50 \mu \mathrm{L})$ which corresponds to a concentration of $250 \mathrm{\mu g} \mathrm{kg}^{-1}$ of internal standard in the feed material. To this acetonitrile $(12 \mathrm{~mL})$ was added and the tubes were vortexed (20 secs). Anhydrous sodium sulphate $(3.5 \mathrm{~g})$ was added to this slurry which was shaken (30 mins) and centrifuged (5100rpm for 20 $\mathrm{min})$. The organic layer was transferred to a clean polypropylene tube $(15 \mathrm{~mL})$ and evaporated at $50^{\circ} \mathrm{C}$ to 6 $\mathrm{mL}$ under nitrogen. Hexane $(5 \mathrm{~mL})$ was added and the tubes contents were vortexed (30 secs) and centrifuged (3750 rpm for $20 \mathrm{~min}$ ). The hexane layer was discarded and the extracts were evaporated to dryness at $50^{\circ} \mathrm{C}$ under a nitrogen stream. The extract was reconstituted in water: acetonitrile $(85: 15,800 \mu \mathrm{L})$ and vortexed thoroughly for 45 secs. The sample underwent an ultracentrifugation step at $13750 \mathrm{rpm}$ for $30 \mathrm{mins}$. This centrifugation step separated the sample into two distinct layers. $200 \mu \mathrm{L}$ of the clear lower layer (containing the analytes) was transferred into an LC-MS vial. An aliquot $(20 \mu \mathrm{L})$ was injected onto the LC column.

\subsection{Matrix Extracted Calibration Curves}

Quantitation was carried out using matrix extracted calibration curves. Blank pig and poultry feed samples were used. These samples were fortified with mixed working standard and submitted to the full extraction procedure. Matrix extracted calibration curves were performed with every batch. Six different feed samples are fortified with internal standard and mixed working standard yielding a calibration range of 0 to $1000 \mu \mathrm{gg}^{-1}$ for all the 11 quantitation analytes. Calibration curves were prepared by plotting the response factor (the ratio of peak area analyte over peak area of internal standard) against analyte concentration. Five internal standards were used; d3DMZ, d3-RNZ, d3-IPZ, d5-CAP and Sulfaphenazole. For those compounds for which no suitable deuterated internal standard could be acquired; MNZ, CLOP, DIN, ETHO and CAR, d3-DMZ was used as an internal standard. For each analyte; calibration curves were linear in the given range with a correlation coefficient of at least 0.98 . In the case of the 3 qualitative analytes, TYL, VIR and OLA no suitable internal standard could be found. This resulted in poor linearity as matrix effects could not be corrected for in a repeatable manner. For these analytes six different feed samples were fortified; one at $0 \mu \mathrm{g} \mathrm{kg}^{-1}$ and five at the 100 $\mu \mathrm{kg}^{-1}$. d3-DMZ was used as an internal standard for these in order to compensate for any extraction errors. 


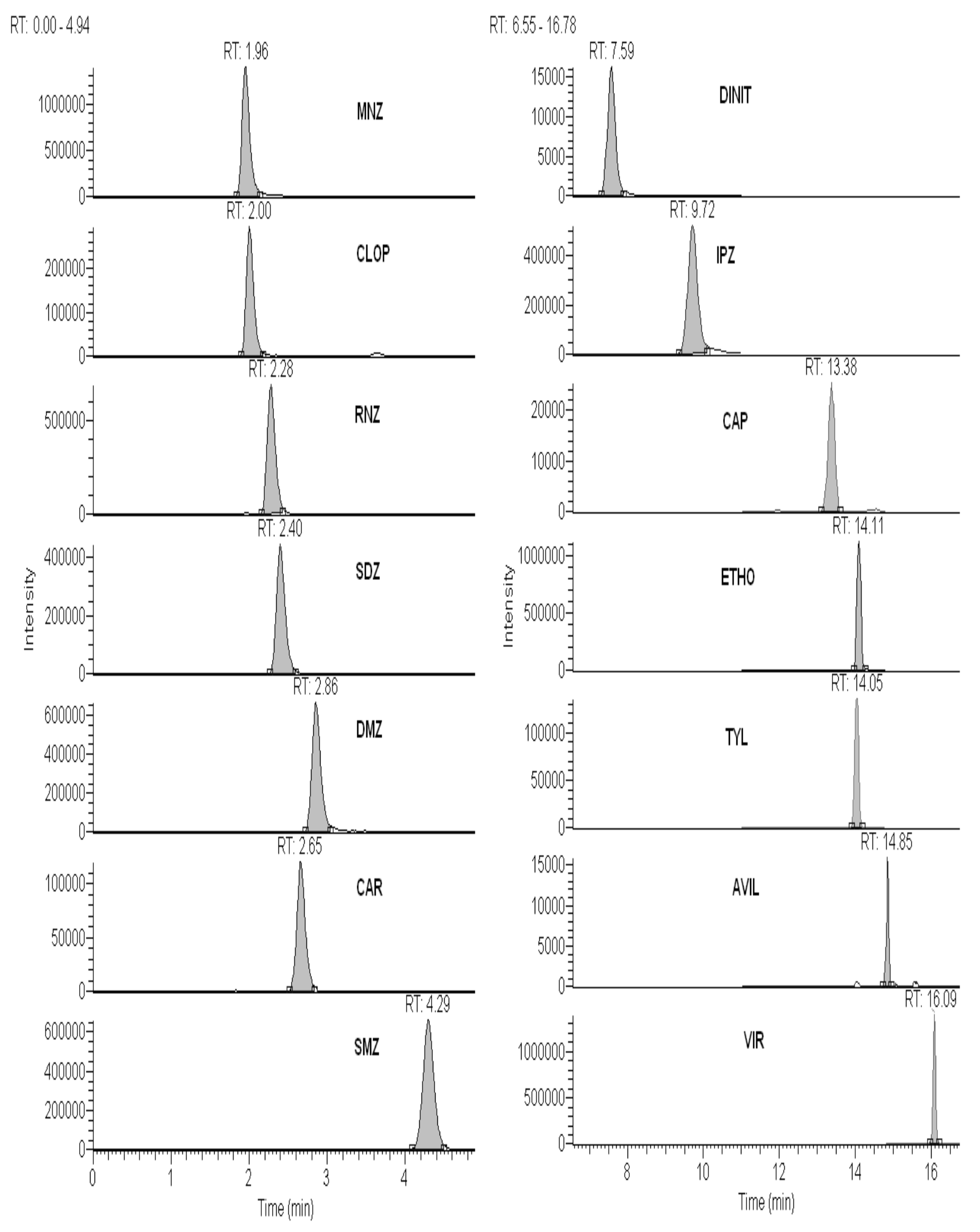

Figure 1a: Chromatograms of Feed Fortified at a level equal to $100 \mu \mathrm{g} \mathrm{kg}^{-1}$ for all 14 compounds. 


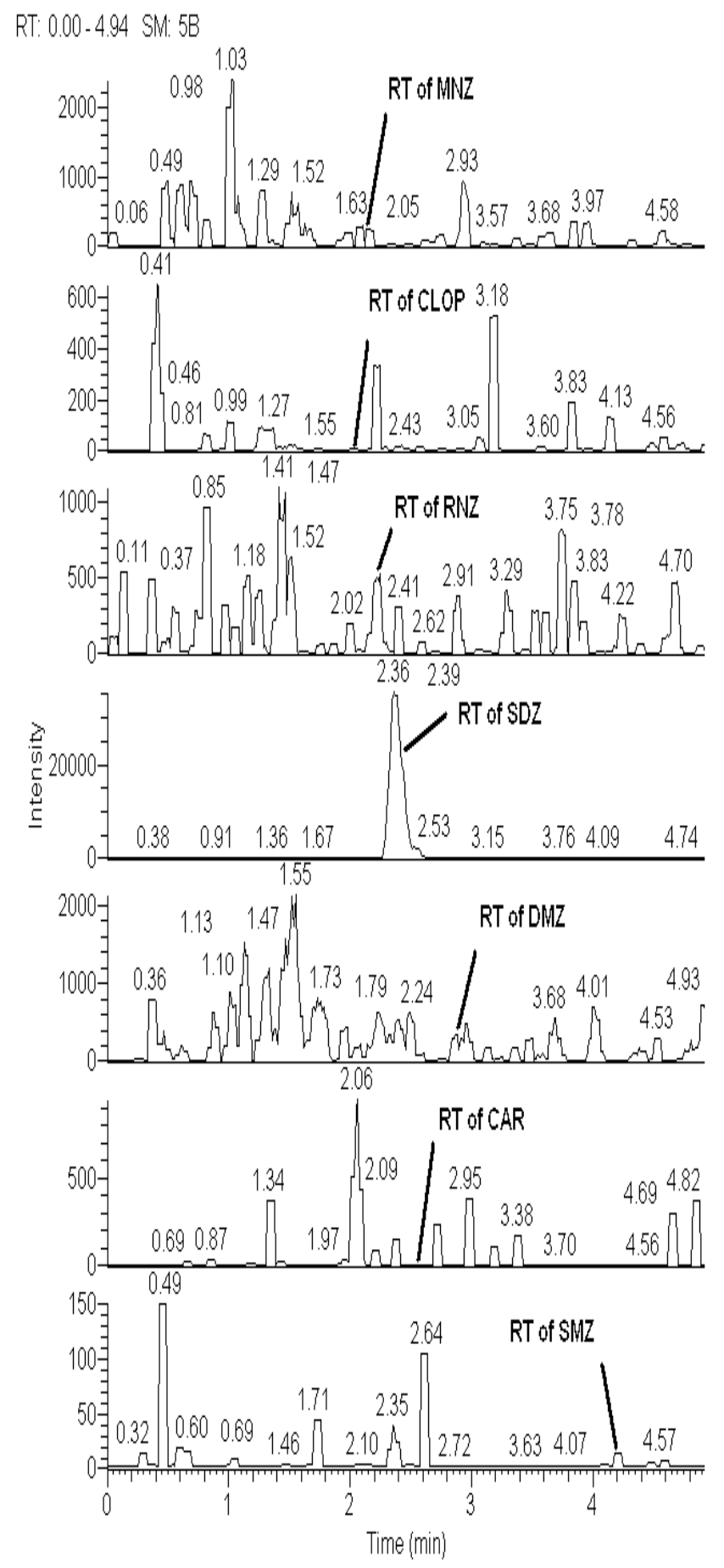

Figure 1b: Chromatograms of Blank Feed

\section{$2.6 \quad$ Method validation}

LC-MS/MS identification criteria were verified throughout the validation study by monitoring relative retention times and relative ion intensities. LC-MS/MS identification criteria as set out in the Commission Decision 2002/657 were verified throughout the validation of the method.
RT: $6.55-16.78$

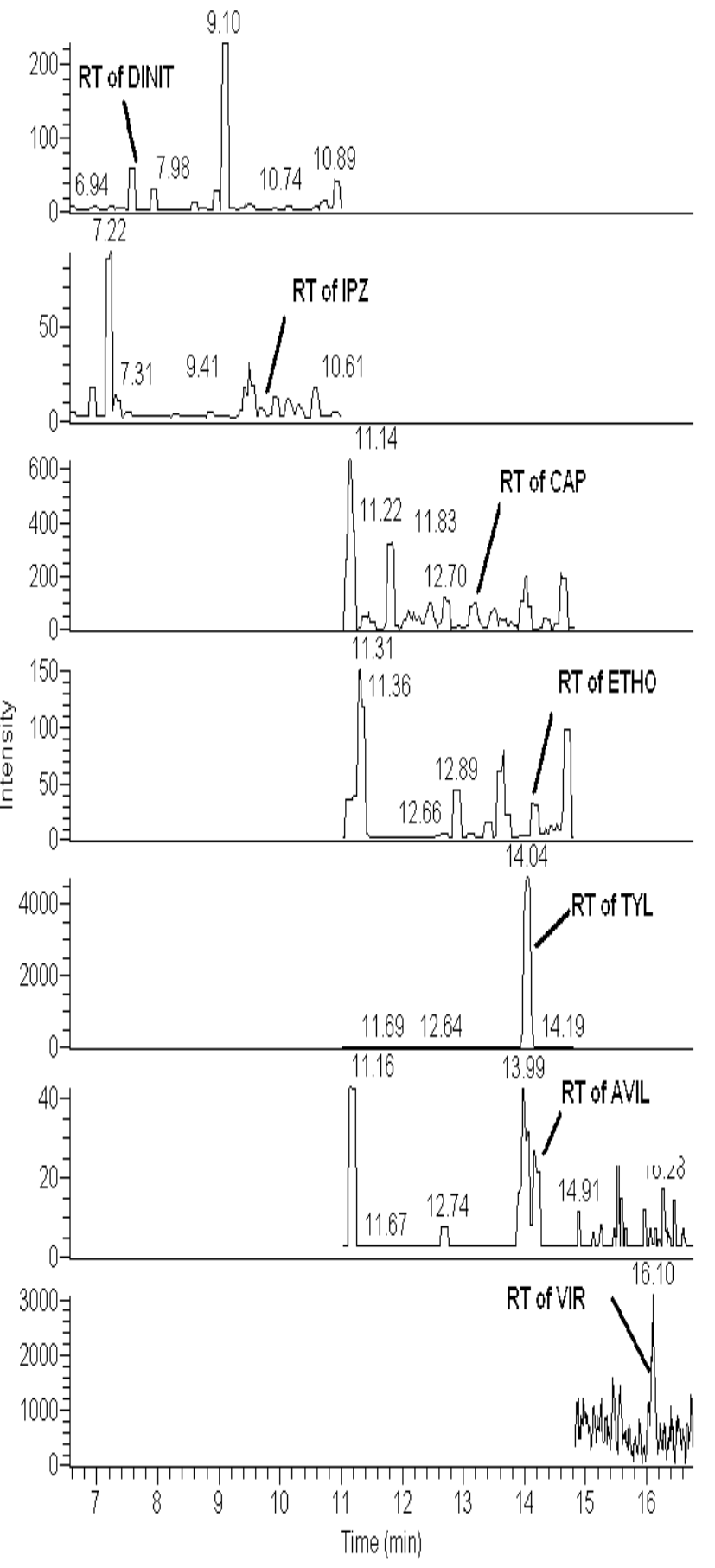

Several method validation parameters were determined including linearity, specificity, trueness, precision (repeatability and within-laboratory reproducibility). Specificity was determined by analysing a number of different blank animal feed samples sourced from different mills. To investigate the linearity of the method, matrixextracted calibration curves were prepared and run with each of the validation batches to give 6 point calibration curves in the range of 0 to $1000 \mu \mathrm{g} \mathrm{kg}^{-1}$ for all eleven quantitation analytes. To ensure linearity across the range 


\section{Prohibited Medicinal Additives in Feed}

of different feed samples that could be encountered for these species a different type of feed alternating between pig and poultry was used for each calibration point.

Since no certified reference materials were available for the analytes and matrices of interest, the trueness from fortified negative samples was measured as an alternative to trueness. The trueness and precision of the method were determined through the analysis of negative pig and poultry compound feed fortified in six replicates at $100 \mathrm{~g} \mathrm{~kg} \mathrm{k}^{-1}, 500$ $\mu \mathrm{g} \mathrm{kg}-1$ and $1000 \mu \mathrm{g} \mathrm{kg}^{-1}$ with the eleven quantifiable analytes for a total of 18 samples. This was repeated on three separate days. For the three qualititative analytes all 18 samples were fortified at $100 \mathrm{\mu g} \mathrm{kg}^{-1}$. The type of feed was varied for each of the six replicates in ordered to ensure that the method was fully fit for purpose. From these three separate validation days an estimation of trueness, precision (repeatability and within-laboratory reproducibility) and LC-MS/MS confirmatory criteria were all evaluated.

\section{Results and Discussion}

\subsection{LC-MS/MS Optimisation}

The LC-MS/MS method was developed to provide confirmatory data for the analysis of 14 antibiotics in pig and poultry compound feed. The MS/MS fragmentation conditions were investigated and collision energies were optimised for each individual compound to give best response. For a method to be deemed confirmatory under Commission Decision 2002/657/EC it must yield 4 identification points. In this method a precursor ion (parent mass) and two product ions (corresponding to strong and weak ion) were monitored for each analyte (Tables 1a and 1b). This yielded 4 identification points ( 1 for the precursor ion and 1.5 for each product ion) hence it can be deemed a confirmatory method. In addition to this relative retention times and ion ratios were monitored for each compound and evaluated to ensure that they are within acceptable ranges as stated in CD 2002/657/EC. As this method involved positive and negative ionisation switching the MS/MS method had to be segmented. The LC gradient was optimised in order to have as an efficient run time as possible in order to allow successful segmentation of the MS/MS method. Only when the positive and negative ionisation switching was isolated to one segment was there enough data points for each peak. Lowering scan time and dwell time of the instrument was not sufficient to achieve this. For a method to achieve reliable quantitation each analyte peak should have at least 10-12 data points. The LC gradient along with segmentation permitted for the analysis of all 14 analytes in a complete run time of 26 minutes with each peak having a minimum of 12 data points.

\subsection{Sample Extraction Development}

The development of the extraction method faced two major obstacles; one the need to extract a wide variety of analytes with a single extraction and the other the need to purify the sample sufficiently without losing the analytes in question. A variety of extraction solutions including water, acetonitrile and methanol and various mixtures of the three were tested. Immediately it was visibly evident that methanol and water extracted far more matrix contaminants than acetonitrile and this resulted in lower recoveries for the analytes using these extraction solvents. It was also observed that acetonitrile consistently extracted the broad range of analytes therefore acetonitrile was chosen as the extraction solvent. The next stage was to sufficiently clean up the acetonitrile extract in order to determine down to the levels of interest. The use of anhydrous sodium sulphate in sample clean up when extracting these analytes has been previously seen. [Stubbings et al., 2009]. Hence the use of anhydrous sodium sulphate was investigated followed by addition of a hexane wash step. This purification procedure sufficiently removed background interferences resulting in the fact that a SPE clean-up step was not needed. The purification was completed when the reconstituted extract underwent an ultracentrifugation step. This removed further interferences and also allowed all analytes to be determined at levels in the $\mu \mathrm{g} \mathrm{kg}^{-1}$ range.

\subsection{Internal Standard Selection}

While the extraction method allowed all analytes to be seen in the $\mu \mathrm{g} \mathrm{kg}^{-1}$ range the variability in sample recovery was noticeable from feed sample to feed sample. To overcome this problem the sourcing of suitable internal standards was pursued. In some cases deuterated analogues were available for the analytes such as d3-DMZ, d3-IPZ, d3-RNZ and d5-CAP. These corrected well for all variabilities encountered in extraction. Sulfaphenazole is a sulphonamide and it has been used as an internal standard for sulfonamides in previous work [McDonald et al., 2009]. This was used for SDZ and SMZ compounds and corrected sufficiently for them. Erythromycin was tried for use with VIR, TYL and AVIL but did not correct consistently well for them. As a last attempt the internal standards used for other compounds were used for the remaining compounds without internal standards. It was observed that d3-DMZ extracted consistently and as a result could be used as an internal standard for CLOP, CAR, DIN and ETH. This allowed for eleven compounds to be analysed quantitatively. For the remaining three compounds VIR, TYL and AVIL no suitable internal standard could be identified. Therefore the method could only be used as a qualitative extraction method for these compounds.

\subsection{Validation Approach Selection}


As of yet no official EU validation protocol exists for the analysis of veterinary drugs in animal feed. Therefore a validation protocol was designed in order to best show that the method was fit for purpose. It was seen in development the variability due to the matrix feed is significant. In order to prove that the method would extract all analytes in a wide range of pig and poultry compound feed it was decided that feed samples would be varied as much as possible. For each of the calibration curve points a different feed would be used on each validation day to ensure linearity held through for all feeds. Eighteen samples were analysed on each day of the three validation days containing six different types of animal. A level of $100 \mu \mathrm{g} \mathrm{kg}$

${ }^{1}$ was chosen as a reporting level and this is significantly lower for the majority of the analytes presented in this paper than observed in previous methods. SIMBAG study suggested levels around $1000 \mu \mathrm{g} \mathrm{kg}^{-1}$ but it was felt that as these compounds are banned they should not be present at any level. These compounds are prohibited for use as feed additives and therefore these compounds should not be present at any level and therefore the ALARA (as low as reasonably achievable) principle was adopted. Work carried out prior to validation indicated that a level of $100 \mu \mathrm{g} \mathrm{kg}^{-1}$ was achievable. This was chosen as it was felt that the method could be used to determine this level on a routine basis for all analytes. For the three qualitative analytes TYL, VIR, OLA it was decided that all eighteen samples on the three different days would be fortified at the reporting level of $100 \mathrm{\mu g} \mathrm{kg}^{-1}$. The measurement of uncertainty for each analyte would be calculated and added onto the 100 $\mu \mathrm{gg}^{-1}$ level and give us a value above which would result in a positive. For the eleven quantitative analytes a different approach was taken. The eighteen samples on the three days would be made up of six replicates of 100,500 and $1000 \mu \mathrm{g} \mathrm{kg}^{-1}$. This was done in order to validate the method over the complete calibration range for which positive results might be obtained. Specificity, trueness, precision (repeatability and within-laboratory reproducibility); along with confirmatory criteria laid out Commission Decision 2002/657 were determined during validation.

\subsection{Specificity}

The technique of LC-MS/MS itself offers a great deal of specificity and selectivity. To establish the specificity and selectivity of the method 18 blank pig and poultry compound feed samples and samples fortified with all 14 analytes were analysed over the 3 validation days. All blank samples showed no interfering peaks in the area of interest for any of the analytes except for sulfadiazine. This is as a result of low levels of sulfadiazine found in the majority of feed samples available. Sulfadiazine is still permitted to be used in medicated feed and this might possibly be the reason for low levels been found in the feed. In order to correct for this, the feed samples were analysed prior to validation and the response observed for SDZ was subtracted from the results achieved during the validation procedure. Although this corrected the results somewhat, the variability in the background sulfadiazine resulted in worse validation results for this compound than the others. Chromatograms of blank feed and feed fortified at $100 \mu \mathrm{g}$ $\mathrm{kg}^{-1}$ for each of the fourteen analytes are seen in Figure 1a and $1 \mathrm{~b}$.

\subsection{Linearity of Response}

The linearity of the chromatographic response was tested with matrix extracted calibration curves using six calibration points in the range of $0-1000 \mu \mathrm{kg}^{-1}$ for all eleven quantitative analytes on each of the validation days. The regression coefficients for all the analytes on each of the validation days in were greater than 0.98 .

\subsection{Ion Ratios}

Two transition ions were monitored for each of the fourteen analytes. The most intense was used for quantitation. Ion ratios were calculated for all analytes. The ion ratio is a ratio of ion responses. The ratios of weak ion responses/strong ion responses are presented in Table 2. All ion ratios of samples were within tolerances as set out by European criteria when compared with standards used during validation. Control charts were used to ensure all ion ratios were acceptable. The example of metronidazole is seen in Figure 2.

\subsection{Relative Retention Times (RRT)}

RRTs were calculated for all fourteen analytes in this method by calculating the ratio of the retention time of the analyte over the retention time of its corresponding internal standards. The RRTs tolerance for LC-MS/MS of $2.5 \%$ was adhered to when standards were compared to samples in the validation runs. Control charts were again used to ensure all ion ratios were acceptable. The example of metronidazole is seen in Figure 3. The typical RRT for all the analytes are shown in Table 2.

\subsection{Trueness}

The trueness of the method was determined by fortifying 18 replicate feed samples on three separate days. For the eleven quantitative analytes six replicates were fortified at $100,500,1000 \mu \mathrm{g} \mathrm{kg}^{-1}$ while the three qualitative analytes were all spiked at $100 \mu \mathrm{g} \mathrm{kg}^{-1}$ for the 18 replicates. Mean corrected trueness $(n=6)$ of the analytes, determined in the three separate validation batches, are shown in Table 2 ranging between 89.2 and 103.3 for the fourteen analytes in pig and poultry feed. No recovery was determined as the use of internal standards means that each sample is individually corrected for. 
Table 2. Validation results for Accuracy, Repeatability, Reproducibility and Measurement Uncertainty (MU) and Confirmatory data of typical ion ratios and relative retention times(RRT) for all 14 analytes.

\begin{tabular}{|c|c|c|c|c|c|c|c|c|}
\hline Analyte & $\begin{array}{l}\text { Internal } \\
\text { Standard }\end{array}$ & $\begin{array}{c}\text { Accuracy } \\
(\%)\end{array}$ & $\begin{array}{l}\text { Repeat } \\
\% \text { RSD }\end{array}$ & $\begin{array}{l}\text { Reprod } \\
\% \text { RSD }\end{array}$ & $\begin{array}{l}\text { MU } \\
(\%)\end{array}$ & $\begin{array}{c}\text { Typical } \\
\text { RRT }\end{array}$ & $\begin{array}{c}\text { Typical } \\
\text { Ion Ratio }\end{array}$ & $\begin{array}{c}\text { Cut-Off } \\
\text { Level } \\
\mu \mathrm{g} / \mathrm{kg}\end{array}$ \\
\hline $\mathrm{DMZ}$ & DMZ-d3 & 98.9 & 4.5 & 8.9 & 27 & 1.0100 & 0.2344 & 100 \\
\hline RNZ & RNZ-d3 & 99.1 & 6.3 & 9.0 & 27 & 1.0053 & 0.0395 & 100 \\
\hline MNZ & DMZ-d3 & 102.5 & 5.8 & 9.3 & 28 & 0.6911 & 0.2964 & 100 \\
\hline IPZ & IPZ-d3 & 99.4 & 4.3 & 7.2 & 24 & 1.0164 & 0.8382 & 100 \\
\hline SDZ & SPZ & 101.4 & 23.3 & 28.0 & 84 & 0.1666 & 0.4667 & 100 \\
\hline SMZ & SPZ & 101.4 & 16.8 & 20.6 & 55 & 0.2987 & 0.2815 & 100 \\
\hline CAR & DMZ-d3 & 99.9 & 12.6 & 13.9 & 42 & 0.9466 & 0.1610 & 100 \\
\hline CAP & CAP-d5 & 101.2 & 11.4 & 12.0 & 36 & 1.0082 & 0.8108 & 100 \\
\hline CLOP & DMZ-d3 & 103.3 & 10.8 & 16.0 & 48 & 0.7125 & 0.3653 & 100 \\
\hline DINIT & DMZ-d3 & 96.3 & 7.7 & 14.8 & 44 & 2.7345 & 0.1880 & 100 \\
\hline ETH & DMZ-d3 & 99.4 & 9.1 & 16.3 & 49 & 5.0406 & 0.5094 & 100 \\
\hline TYL & DMZ-d3 & 95.6 & 16.8 & 21.8 & 69 & 5.0000 & 0.7275 & 169 \\
\hline VIR & DMZ-d3 & 100.0 & 22.7 & 22.9 & 65 & 5.7381 & 0.3777 & 165 \\
\hline AVIL & DMZ-d3 & 89.2 & 21.1 & 22.0 & 66 & 5.2961 & 0.4851 & 166 \\
\hline
\end{tabular}


Prohibited Medicinal Additives in Feed

\begin{tabular}{|c|c|c|c|c|c|}
\hline \multirow[b]{2}{*}{ Sample } & \multicolumn{5}{|c|}{ Metronidazole } \\
\hline & $\begin{array}{l}\text { Strong lon } \\
\text { Peak Area } \\
\end{array}$ & $\begin{array}{c}\text { Weak lon } \\
\text { Peak Area } \\
\end{array}$ & Ion Ratio & $20 \%+$ & $20 \%-$ \\
\hline Std $100 \mu \mathrm{g} \mathrm{kg}^{-1}$ & 15194729 & 4752084 & 0.3127 & 0.3556 & 0.2371 \\
\hline Std $250 \mu \mathrm{g} \mathrm{kg}^{-1}$ & 42333522 & 12107683 & 0.2860 & 0.3556 & 0.2371 \\
\hline Std $500 \mu \mathrm{g} \mathrm{kg}^{-1}$ & 72310544 & 20962631 & 0.2899 & 0.3556 & 0.2371 \\
\hline Std $750 \mu \mathrm{g} \mathrm{kg}^{-1}$ & 111573188 & 33615028 & 0.3013 & 0.3556 & 0.2371 \\
\hline Std $1000 \mu \mathrm{g} \mathrm{kg}^{-1}$ & 141124965 & 41197657 & 0.2919 & 0.3556 & 0.2371 \\
\hline Level $1 \mathrm{~A}$ & 15930883 & 4802808 & 0.3015 & 0.3556 & 0.2371 \\
\hline Level $1 \mathrm{~B}$ & 13779107 & 4100715 & 0.2976 & 0.3556 & 0.2371 \\
\hline Level $1 \mathrm{C}$ & 15060999 & 4687121 & 0.3112 & 0.3556 & 0.2371 \\
\hline Level $1 \mathrm{D}$ & 14015787 & 4045653 & 0.2886 & 0.3556 & 0.2371 \\
\hline Level $1 \mathrm{E}$ & 14936729 & 4494700 & 0.3009 & 0.3556 & 0.2371 \\
\hline Level $1 \mathrm{~F}$ & 15109412 & 4330588 & 0.2866 & 0.3556 & 0.2371 \\
\hline Level $2 \mathrm{~A}$ & 82300381 & 23812667 & 0.2893 & 0.3556 & 0.2371 \\
\hline Level 2 B & 55668164 & 16886535 & 0.3033 & 0.3556 & 0.2371 \\
\hline Level $2 \mathrm{C}$ & 98201444 & 27970852 & 0.2848 & 0.3556 & 0.2371 \\
\hline Level 2 D & 86217956 & 24778305 & 0.2874 & 0.3556 & 0.2371 \\
\hline Level $2 \mathrm{E}$ & 88044794 & 25699990 & 0.2919 & 0.3556 & 0.2371 \\
\hline Level $2 \mathrm{~F}$ & 88971771 & 27257657 & 0.3064 & 0.3556 & 0.2371 \\
\hline Level $3 \mathrm{~A}$ & 183983033 & 50847934 & 0.2764 & 0.3556 & 0.2371 \\
\hline Level 3 B & 157024199 & 45227252 & 0.2880 & 0.3556 & 0.2371 \\
\hline Level $3 \mathrm{C}$ & 170214626 & 50069929 & 0.2942 & 0.3556 & 0.2371 \\
\hline Level 3 D & 170597905 & 48706960 & 0.2855 & 0.3556 & 0.2371 \\
\hline Level $3 \mathrm{E}$ & 177451858 & 50805992 & 0.2863 & 0.3556 & 0.2371 \\
\hline Level $3 \mathrm{~F}$ & 163816078 & 47947886 & 0.2927 & 0.3556 & 0.2371 \\
\hline
\end{tabular}

Average Std Ion Ratio: 0.2964

Average $+20 \% \quad: 0.3556$

Average $-20 \% \quad: 0.2371$

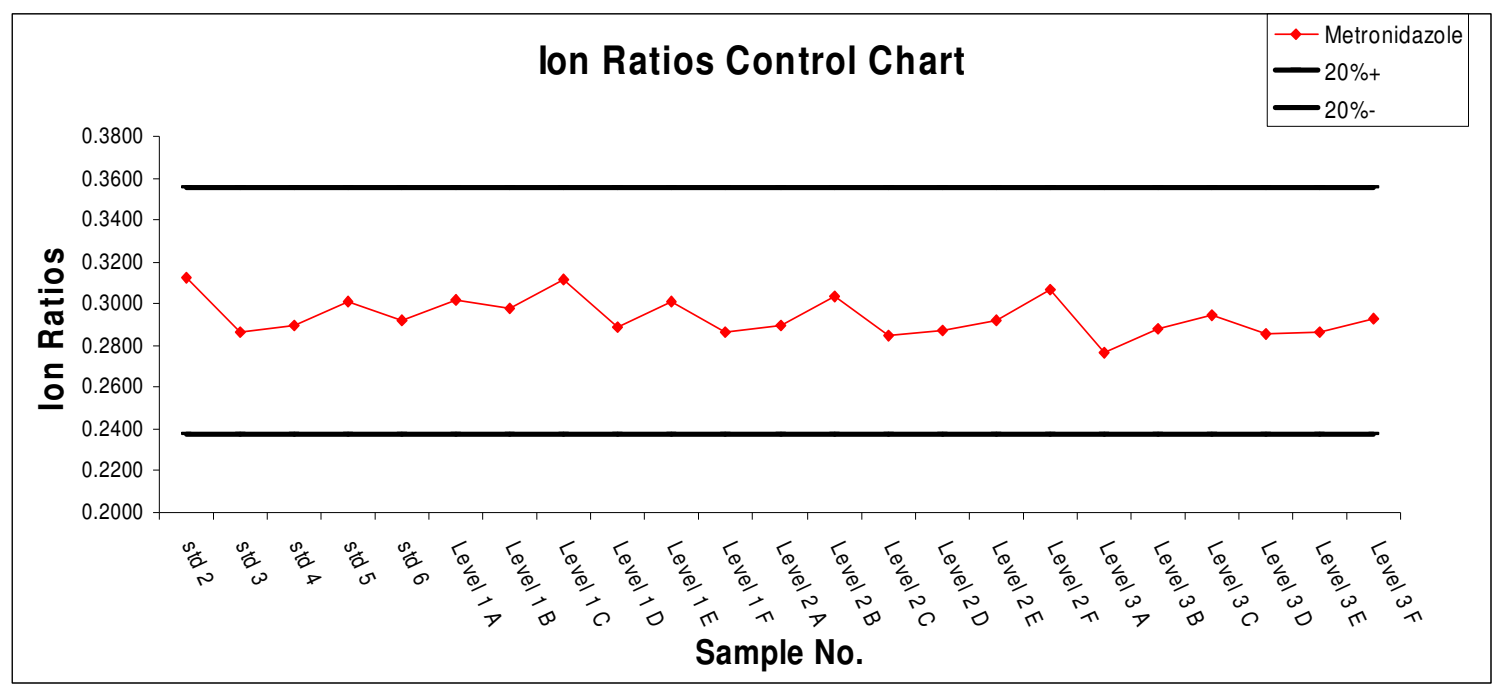

Figure 2. Control Chart for Ion Ratio of Metronidazole 


\section{Prohibited Medicinal Additives in Feed}

\begin{tabular}{|c|l|c|c|c|c|c|}
\hline & & \multicolumn{5}{|c|}{ Metronidazole } \\
\cline { 3 - 7 } & Sample & $\begin{array}{c}\text { Retention } \\
\text { Time }\end{array}$ & $\begin{array}{c}\text { Retention Time } \\
\text { of Internal } \\
\text { Standard }\end{array}$ & $\begin{array}{c}\text { Relative } \\
\text { Retention Time } \\
\text { (RRT) }\end{array}$ & $2.5 \%+$ & $2.5 \%-$ \\
\hline \hline Std2 & Std 100 & 1.94 & 2.82 & 0.6879 & 0.7084 & 0.6738 \\
\hline Std3 & Std 250 & 1.95 & 2.80 & 0.6964 & 0.7084 & 0.6738 \\
\hline Std4 & Std 500 & 1.94 & 2.82 & 0.6879 & 0.7084 & 0.6738 \\
\hline Std5 & Std 750 & 1.94 & 2.80 & 0.6929 & 0.7084 & 0.6738 \\
\hline Std6 & Std 1000 & 1.94 & 2.81 & 0.6904 & 0.7084 & 0.6738 \\
\hline & Level 1 A & 1.95 & 2.82 & 0.6915 & 0.7084 & 0.6738 \\
\hline & Level 1 B & 1.94 & 2.82 & 0.6879 & 0.7084 & 0.6738 \\
\hline & Level 1 C & 1.94 & 2.80 & 0.6929 & 0.7084 & 0.6738 \\
\hline & Level 1 D & 1.93 & 2.80 & 0.6893 & 0.7084 & 0.6738 \\
\hline & Level 1 E & 1.95 & 2.80 & 0.6964 & 0.7084 & 0.6738 \\
\hline & Level 1 F & 1.94 & 2.82 & 0.6879 & 0.7084 & 0.6738 \\
\hline & Level 2 A & 1.94 & 2.82 & 0.6879 & 0.7084 & 0.6738 \\
\hline & Level 2 B & 1.94 & 2.82 & 0.6879 & 0.7084 & 0.6738 \\
\hline & Level 2 C & 1.94 & 2.82 & 0.6879 & 0.7084 & 0.6738 \\
\hline & Level 2 D & 1.94 & 2.82 & 0.6879 & 0.7084 & 0.6738 \\
\hline & Level 2 E & 1.94 & 2.82 & 0.6879 & 0.7084 & 0.6738 \\
\hline & Level 2 F & 1.94 & 2.82 & 0.6879 & 0.7084 & 0.6738 \\
\hline & Level 3 A & 1.96 & 2.82 & 0.6950 & 0.7084 & 0.6738 \\
\hline & Level 3 B & 1.94 & 2.80 & 0.6929 & 0.7084 & 0.6738 \\
\hline & Level 3 C & 1.94 & 2.80 & 0.6929 & 0.7084 & 0.6738 \\
\hline & Level 3 D & 1.94 & 2.80 & 0.6929 & 0.7084 & 0.6738 \\
\hline & Level 3 E & 1.95 & 2.82 & 0.6915 & 0.7084 & 0.6738 \\
\hline & Level 3 F & 1.95 & 2.82 & 0.6915 & 0.7084 & 0.6738 \\
\hline & & & & & & \\
\hline
\end{tabular}

\section{Average RRT: 0.6911}

Average $+2.5 \%: 0.7081$

Average $-2.5 \%: 0.6738$

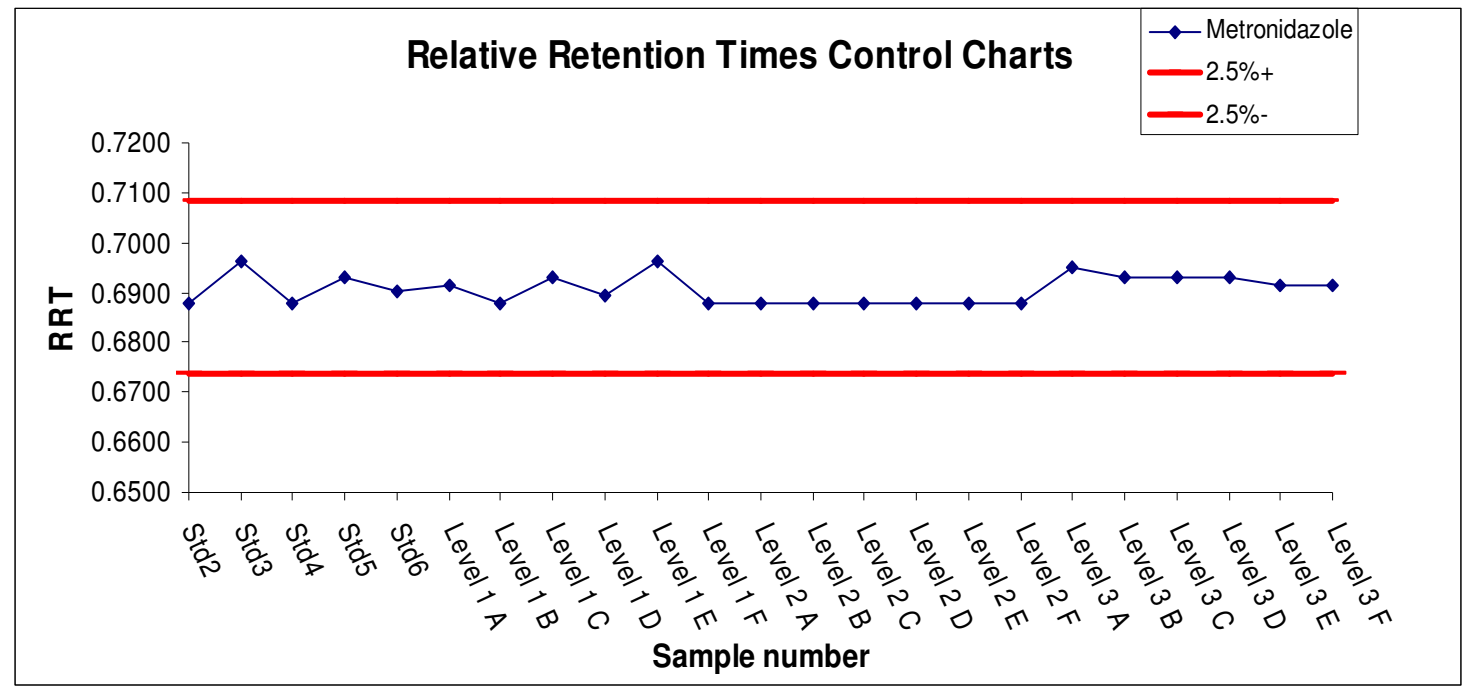

Figure 3. RRT Control Chart for Metronidazole 


\subsection{Precision (Repeatability and within-lab Reproducibility)}

Repeatability (within-day) and within-laboratory reproducibility (different days and operators) were determined by calculating relative standard deviations (RSD, \%) for the repeated measurements. Overall repeatability (RSD, \%) and within-laboratory reproducibility (RSD, \%) ranged from 4.3 to $23.3 \%$ and from 7.2 to $28.0 \%$, respectively, for all analytes (Table 2 ).

The usefulness of suitable deuterated internal standards is demonstrated in the acceptable results for repeatability and within-laboratory reproducibility obtained for DMZ, RNZ, IPZ and CAP. Although deuterated analogues could not be obtained by our laboratory for use as internal standards for over half of the analytes investigated, acceptable repeatability and within-laboratory reproducibility is obtained by using the d3-DMZ for MNZ, CLOP, DINIT, ETH, CAR and using sulfaphenazole for SMZ. Less favorable is the situation for SDZ. Rather high RSD values were obtained for both the repeatability and withinlaboratory reproducibility of SDZ (between 20 and 28\%), even when applying correction by means of an internal standard (sulfaphenazole). This is as a result of the variability for the feed sample due to the low levels of SDZ present in the feed.

\subsection{Measurement of Uncertainty}

The measurement uncertainty (MU) was estimated by taking into account the within laboratory reproducibility over days 1, 2 and 3 . This value was multiplied by a coverage factor of three to give an overall figure for the MU. This approach of using the within laboratory reproducibility as a good estimator of measurement of uncertainty is taken from the SANCO/2004/2726rev4 document. It recommends using the within laboratory reproducibility and using a coverage factor of 2.33 to estimate expanded uncertainty, however it was felt that not all the environmental factors that could be varied over the course of the validation were examined. Therefore a coverage factor of 2.33 may underestimate the true uncertainty of the method and instead a value of 3 was chosen to give a more realistic value for the true uncertainty. Values for $\mathrm{MU}$ are seen in Table 2 and lie between 24 and $84 \%$ for all the analytes.

Higher MUs are seen in some compounds with no deuterated analogues for use as internal standards which is expected. In particular the MU for SDZ (84\%) is the highest observed for any of the analytes investigated due to problems with low levels of SDZ observed in the majority of feed used. This resulted in greater variability in results achieved for SDZ and in turn increased its MU.

\section{Conclusions}

The objective of this work was to develop a rapid multiclass confirmatory method capable of analysing for fourteen prohibited medicinal additives in pig and poultry compound feed at $100 \mu \mathrm{g} \mathrm{kg}^{-1}$ and to validate in such a way as to best show the method as fit for purpose. This was successfully completed to allow for the quantification of 10 analytes and qualitative analysis of 4 analytes.

The method can be considered as rapid, as it utilises an efficient extraction protocol without the use of large sample sizes, extraction volumes and SPE. It also utilises chromatography which separates all analytes in a total run time of only 26 minutes. The method permits the analysis of 14 medicinal additives in pig and poultry compound feed which has not been seen in literature before.

The obtained confirmatory criteria of ion ratios and relative retention times fulfill the requirements laid down in Commission Decision 2002/657/EC. The calculation of all relevant performance characteristics was performed during validation. This study shows that the developed method meets the desired sensitivity of $100 \mu \mathrm{g} \mathrm{kg}^{-1}$ for all the compounds. The method performs satisfactorily in terms of trueness and repeatability for each of the analytes investigated with the exception of sulfadiazine due to the utilisation of five different internal standards. The values achieved for trueness, \%RSD and measurement of uncertainty all fall within acceptable ranges except for sulfadiazine. The applicability of the method for use on various types of pig and poultry compound feed was demonstrated by the satisfactory results obtained from the validation. The validation data shows that the method allows for the quantitation of 10 analytes and the qualitative analysis of 3 analytes. While sulfadiazine was validated in order to be quantified the validation results achieved were not acceptable. This is as a result of varying background sulfadiazine in the feeds that were used in validation. That said, the reduced number of analytical steps within the method makes it very amenable for high through-put regulatory monitoring of these compounds and enforcing Commission Recommendation 2005/925/EC.

The method developed in this study is an improvement on existing methods as it allows for the analysis of an increased number of analytes in this matrix. It also allows for reduced sample preparation times and solvent usage than other published methods. The objective of this work was to develop a rapid confirmatory method capable of identifying, confirming and quantifying eleven nitroimidazole compounds in egg at $\mu \mathrm{g} \mathrm{kg}^{-1}$ levels and to validate according to the requirements in Commission Decision 2002/657/EC and this was successfully completed. 


\section{Prohibited Medicinal Additives in Feed}

The method can be considered as rapid, as it utilises only a hexane wash and omits the use of the time consuming SPE step, it also utilises chromatography which separates all analytes in a total run time of only 20 minutes. The method includes 11 nitroimidazole compounds including seven that are suggested by the CRL in Berlin to be analysed as well as other nitroimidazoles that are rarely if at all analysed such as tinidazole, ornidazole and carnidazole.

\section{Acknowledgements}

This work was funded by the DIT Strand 1 Projects. The author would like to thank Dublin Institute of Technology, School of Chemical and Pharmaceutical Sciences, Kevin Street, Dublin 8, Ireland for the opportunity to carry out this work and also the staff at The State Laboratory, Co. Kildare for their practical assistance.

\section{References}

Barbosa J., Moura S., Barbosa S., Ramos F., da Silveira M. 2007. Determination of nitrofurans in animal feeds by liquid chromatography-UV photodiode array detection and liquid chromatography-ionspray tandem mass spectrometry. Anal. Chim. Acta; 586:359-365

Capitan-Vallvey L. F. , Ariza A., Checa R., Navas N. 2007. Liquid Chromatography-Mass Spectrometry Determination of Six 5Nitroimidazoles in Animal Feedstuff. Chromatographia; 65:283-290

Civitareale C., Fiori M., Ballerini A., Brambilla G. 2004. Identification and quantification method of spiramycin and tylosin in feedingstuffs with HPLC-UV/DAD at $1 \mathrm{ppm}$ level. J. Pharmaceut. Biomed. Anal.; 36:317-325.

Commission Decision 2002/657/EC of 12 August 2002 implementing Council Directive 96/23/EC concerning the performance of analytical methods and interpretation of results. Off. J. Eur. Commun. 2002, L221, 8

COMMISSION REGULATION (EU) No 37/2010 of 22 December 2009 on pharmacologically active substances and their classification regarding maximum residue limits in foodstuffs of animal origin.

COMMISSION RECOMMENDATION 2005/925/EC of 14 December 2005 on the coordinated inspection programme in the field of animal nutrition for the year 2006 in accordance with Council Directive 95/53/EC. Off. J. Eur. Commun. 2005, L337/51

COUNCIL REGULATION (EC) No 2821/98 of 17 December 1998 amending, as regards withdrawal of the authorisation of certain antibiotics, Directive 70/524/EEC concerning additives in feedingstuffs. Off. J. Eur. Commun. 1998, L351/4

de Jong J. 2005. Screening and Identification Methods for Official Control of Banned Antibiotics and Growth Promoters in Feedingstuffs. Final Technical Report, (2005), 1-78.

Dusi G., Faggionato E., Gamba V., Baiguera A. 2000. Determination of nicarbazin and clopidol in poultry feeds by liquid chromatography. J. Chromatogr. A; 882:79-84

Galarini R., Fioroni L., Angelucci F., Tovo G.R., Elisa Cristofani E. 2009. Simultaneous determination of eleven quinolones in animal feed by liquid chromatography with fluorescence and ultraviolet absorbance detection. J. Chromatogr. A; 1216: 8158-8164

Hutchinson M.J., Young P.B., Kennedy D.G. 2005. Confirmatory method for the analysis of carbadox and olaquindox in porcine feedingstuffs using LC-electrospray MS-MS. Food Addit. Contamin.; 22:113-119.

Kesiunaite G., Naujalis E., Padarauskas A. 2008. Matrix solidphase dispersion extraction of carbadox and olaquindox in feed followed by hydrophilic interaction ultra-high-pressure liquid chromatographic analysis. J. Chromatogr. A; 1209:83-87

McDonald M., Mannion C., Rafter P. 2009. A confirmatory method for the simultaneous extraction, separation, identification and quantification of tetracycline, sulphonamide, trimethoprim and dapsone residues in muscle by ultra-high-performance liquid chromatography-tandem mass spectrometry according to Commission Decision 2002/657/EC. J. Chromatogr. A; 1216:81108116.

Pecorelli I., Galarini R., Bibi R., Floridi Al., Casciarri E., Floridi A. 2003. Simultaneous determination of 13 quinolones from feeds using accelerated solvent extraction and liquid chromatography. Anal. Chim. Acta; 483: 81-89

Stubbings G., Bigwood T. 2009. The development and validation of a multiclass liquid chromatography tandem mass spectrometry (LC-MS/MS) procedure for the determination of veterinary drug residues in animal tissue using a QuEChERS (QUick, Easy, CHeap, Effective, Rugged and Safe) approach. Anal. Chim. Acta, 637:68-78.

Tan H., Ramachandran P., Cacini W. 1996. High performance liquid chromatographic assay of amprolium and ethopabate in chicken feed using solid-phase extraction. J. Pharmaceut. Biomed. Anal.; 15:259-265

van Holthoon F., Mulder P., van Bennekom E.O., Heskamp H., Zuidema T., van Rhijn H. 2010. Quantitative analysis of penicillins in porcine tissues, milk and animal feed using derivatisation with piperidine and stable isotope dilution liquid chromatography tandem mass spectrometry, Anal Bioanal Chem.;396:3027-3040.

van Poucke C., de Keyser K., Baltusnikiene A., McEvoy J.D.G., van Peteghem C. 2003. Liquid chromatographic-tandem mass spectrometric detection of banned antibacterial growth promoters in animal feed. Anal. Chim. Acta; 483:99-109

van Poucke C., Dumoulin F., van Peteghem C. 2005. Detection of banned antibacterial growth promoters in animal feed by liquid chromatography-tandem mass spectrometry: optimisation of the extraction solvent by experimental design. Anal. Chim. Acta; 529:211-220

Vinas P., Balsalobre N., Hernandez-Cordoba M. 2006. Determination of chloramphenicol residues in animal feeds by liquid chromatography with photo-diode array detection. Anal Chim Acta; 558:11-15

Vincent U., Chedin M., Yasar S., von Holst C. 2008. Determination of ionophore coccidiostats in feedingstuffs by liquid chromatography-tandem mass spectrometry-Part I: Application to targeted feed. J. Pharmaceut. and Biomed. Anal.; 47:750-757 